\title{
Sequential growth factor exposure of human Ad-MSCs improves chondrogenic differentiation in an osteochondral biphasic implant
}

\author{
ALEJANDRO GARCIA-RUIZ ${ }^{1}$, CELIA N. SÁNCHEZ-DOMÍNGUEZ ${ }^{1}$, NIDIA K. MONCADA-SAUCEDO ${ }^{1}$, \\ VANESSA PÉREZ-SILOS ${ }^{1}$, JORGE LARA-ARIAS ${ }^{2}$, IVÁN A. MARINO-MARTÍNEZ ${ }^{3,4}$, \\ ALBERTO CAMACHO-MORALES ${ }^{1,5}$, VÍKTOR J. ROMERO-DIAZ ${ }^{6}$, VÍCTOR PEÑA-MARTINEZ ${ }^{2}$, \\ ROSALÍO RAMOS-PAYÁN ${ }^{7}$, YANKO CASTRO-GOVEA ${ }^{8}$, ROCKY S. TUAN ${ }^{9,10}$, HANG LIN $^{11}$, \\ LIZETH FUENTES-MERA $^{1}$ and ANA MARÍA RIVAS-ESTILLA ${ }^{1}$
}

\begin{abstract}
${ }^{1}$ Biochemistry and Molecular Medicine Department, ${ }^{2}$ Orthopedics and Traumatology Service, ${ }^{3}$ Pathology Department, Faculty of Medicine and University Hospital 'Dr José E. González', Autonomous University of Nuevo Leon; ${ }^{4}$ Experimental Therapies Unit, Center for Research and Development in Health Sciences, Autonomous University of Nuevo Leon; ${ }^{5}$ Neurometabolism Unit, Center for Research and Development in Health Sciences, Autonomous University of Nuevo Leon;

${ }^{6}$ Histology Department, Faculty of Medicine and University Hospital 'Dr José E. González',

Autonomous University of Nuevo Leon, Monterrey, Nuevo Leon 64460; ${ }^{7}$ Microbiology Laboratory,

Faculty of Chemical-Biological Sciences, Autonomous University of Sinaloa, Culiacan, Sinaloa 80040;

${ }^{8}$ Plastic Surgery Department, Faculty of Medicine and University Hospital 'Dr José E. González', Autonomous University of Nuevo Leon, Monterrey, Nuevo Leon 64460, Mexico; ${ }^{9}$ Center for Cellular and Molecular Engineering, Department of Orthopaedic Surgery, University of Pittsburgh;

${ }^{10} \mathrm{McG}$ cwan Institute for Regenerative Medicine, University of Pittsburgh; ${ }^{11}$ Department of Bioengineering, Swanson School of Engineering, University of Pittsburgh, Pittsburgh, PA 15219, USA
\end{abstract}

Received October 30, 2020; Accepted July 28, 2021

DOI: $10.3892 /$ etm.2021.10717

\begin{abstract}
Joint cartilage damage affects 10-12\% of the world's population. Medical treatments improve the short-term quality of life of affected individuals but lack a long-term effect due to injury progression into fibrocartilage. The use
\end{abstract}

Correspondence to: Dr Lizeth Fuentes-Mera or Dr Ana María Rivas-Estilla, Biochemistry and Molecular Medicine Department, Faculty of Medicine and University Hospital 'Dr José E. González', Autonomous University of Nuevo Leon, 235 Dr Jose Eleuterio Gonzalez, Monterrey, Nuevo Leon 64460, México

E-mail: lizeth46@hotmail.com

E-mail: ana.rivasst@uanl.edu.mx

Abbreviations: MSCs, mesenchymal stem cells; Ad-MSCs, adipose-derived MSCs; RT-qPCR, reverse transcription-quantitative PCR; IF, immunofluorescence; CB, cytoskeleton buffer; PTFE, polytetrafluoroethylene; HS, human serum; FGF2, fibroblast growth factor 2; IGF1, insulin-like growth factor 1; THY1, Thy-1 cell surface antigen; ACAN, aggrecan; COMP, cartilage oligomeric matrix protein; COL2A1, collagen type II $\alpha 1$ chain; RUNX2, runt-related transcription factor 2; ALPL, alkaline phosphatase; SPP1, osteopontin; NANOG, Nanog homeobox; OCT3/4, octamer-binding transcription factor; SSEA4, stage-specific embryonic antigen 4

Key words: adipose-derived mesenchymal stem cells, chondrogenic differentiation, biphasic implant, growth factors, xeno-free of mesenchymal stem cells (MSCs) is one of the most promising strategies for tissue regeneration due to their ability to be isolated, expanded and differentiated into metabolically active chondrocytes to achieve long-term restoration. For this purpose, human adipose-derived MSCs (Ad-MSCs) were isolated from lipectomy and grown in xeno-free conditions. To establish the best differentiation potential towards a stable chondrocyte phenotype, isolated Ad-MSCs were sequentially exposed to five differentiation schemes of growth factors in previously designed three-dimensional biphasic scaffolds with incorporation of a decellularized cartilage matrix as a bioactive ingredient, silk fibroin and bone matrix, to generate a system capable of being loaded with pre-differentiated Ad-MSCs, to be used as a clinical implant in cartilage lesions for tissue regeneration. Chondrogenic and osteogenic markers were analyzed by reverse transcription-quantitative PCR and cartilage matrix generation by histology techniques at different time points over 40 days. All groups had an increased expression of chondrogenic markers; however, the use of fibroblast growth factor $2(10 \mathrm{ng} / \mathrm{ml})$ followed by a combination of insulin-like growth factor $1(100 \mathrm{ng} / \mathrm{ml}) / \mathrm{TGF} \beta 1$ $(10 \mathrm{ng} / \mathrm{ml})$ and a final step of exposure to TGF $\beta 1$ alone $(10 \mathrm{ng} / \mathrm{ml})$ resulted in the most optimal chondrogenic signature towards chondrocyte differentiation and the lowest levels of osteogenic expression, while maintaining stable collagen matrix deposition until day 33. This encourages their possible use in osteochondral lesions, with appropriate properties for use in clinical patients. 


\section{Introduction}

Joint cartilage damage derived from trauma, disease and lifetime physical wear affects $10-12 \%$ of the world's population (1). This percentage is continuously growing due to an aging and increasingly overweight society (2). Cartilage consists of an extracellular matrix secreted by chondrocytes (3). This tissue provides multiple mechanical properties, such as elasticity, water retention and friction reduction in joints. The treatment for chondral diseases usually focuses on symptomatic relief by local or systemic drug treatments and repair procedures such as cartilage autograft, autologous chondrocyte implantation and subchondral bone microfracture (4). These treatments improve the short-term life quality of patients but lack long-term effects due to their progression to fibrocartilage tissue without the elastic properties of the native cartilage $(5,6)$.

Novel alternative therapies for long-term restoration of cartilage damage are in constant development. Among these, the use of human mesenchymal stem cells (MSCs), alone or in combination with biological scaffolds, is the most promising procedure. MSCs have been proposed as an innovative method in regenerative medicine for the development of cell-based therapies and are currently being evaluated in a large number of clinical trials for cartilage damage repair (7). In vitro, MSCs may be differentiated into a chondrocyte-like phenotype by the use of chemical stimuli such as insulin-like growth factors (IGF), bone morphogenic proteins (BMPs) and TGF (8).

Multiple growth factors have been identified as promoters of differentiation from MSCs to chondrocytes, such as fibroblast growth factor 2 (FGF2), TGF $\beta 1$, TGF $\beta 3$, BMP2, BMP7 and IGF1 (9-11). Other differentiation techniques include co-culture with native chondrocytes and microenvironment modulation, such as the use of bioactive matrices that simulate the biological microenvironment of native chondrocytes, in monolayer conditions or more suitable three-dimensional (3D) scaffolding culture conditions (12). However, these approaches frequently lose effectiveness over time due to hypertrophy of differentiated chondrocytes (13). This hypertrophic process is modulated by a decrease in the expression of the transcription factor SOX9, which serves as the major promoter of chondrogenic differentiation and their metabolic processes, stimulating factors such as collagen type II and proteoglycans, and acting as a suppressor of runt-related transcription factor (RUNX2), which is responsible for the initiation of the ossification mechanism (14). RUNX2 is a key transcription factor in the osteoblastic differentiation process, bone formation and skeletal morphogenesis $(2,14)$. Long-term culture of MSC-derived chondrocytes leads to inhibition of SOX9 and to hypertrophic progression, increasing the expression levels of RUNX2 and matrix replacement by secretion of proteins such as collagen type X, VEGF, MMP13 and alkaline phosphatase (ALPL) (15).

To achieve MSC differentiation into phenotypically stable chondrocytes, and cartilage restoration, it is hypothesized that a precise combination of chondrogenic and osteogenic factors and temporal changes in the local microenvironment is required, along with a $3 \mathrm{D}$ scaffold ready for its use in the repair of human cartilage damage $(16,17)$.

To investigate this, a $3 \mathrm{D}$ scaffold that emulates the biological conditions and microenvironment typical for native chondrocytes was developed to allow human adipose-derived
(Ad)-MSC differentiation and maintenance of phenotypic stability under culture conditions free of animal components (xeno-free). The present results were promising for providing an advanced medical therapy product in areas of chondral damage. In addition, analysis of the differentiation process was performed to study the biological mechanisms involved, which may be helpful in future experiments of MSC differentiation using growth factors (18).

\section{Materials and methods}

Patients and samples. The present study was approved by the Institutional Ethics and Research Committees of the Faculty of Medicine and University Hospital 'Dr José E. González' (HU) of the Autonomous University of Nuevo Leon (Monterrey, México; registry no. PI17-00360). Lower abdominal adipose tissue was collected from the surgical lipoaspirate waste of three healthy females $(\mathrm{BMI}<30)$, that were $>18$ years of age and demonstrated negative serology (HIV, hepatitis B and C virus). Tissue was obtained at the HU between May 2017 and June 2018. The adipose tissue was collected in sterile 50-ml conical tubes (cat. no. 430290; Corning, Inc.) and maintained at $4^{\circ} \mathrm{C}$ for a maximum of $6 \mathrm{~h}$ until processing. All patients provided written informed consent for the use of their tissue.

Ad-MSC isolation under xeno-free conditions. To isolate Ad-MSCs, a modified version of the isolation protocol described in Moncada-Saucedo et al (19) was followed (20). To achieve this, lipoaspirate was centrifuged for $10 \mathrm{~min}$ at $1,000 \mathrm{x}$ g in a $4^{\circ} \mathrm{C}$ refrigerated centrifuge (5804R; Eppendorf), the aqueous phase was discarded and the adipose tissue was washed with PBS (pH 7.4). Tissue was placed in 200-ml sterile bottles and incubated with collagenase I 0.1\% (cat. no. 17018029; Gibco; Thermo Fisher Scientific, Inc.) for $30 \mathrm{~min}$ at $37^{\circ} \mathrm{C}$ with low agitation for tissue digestion and then left to rest without agitation for $5 \mathrm{~min}$ to allow cells to form a sediment at the bottom of the bottles. The fat phase was removed and the aqueous phase and cells were centrifuged at $1,000 \mathrm{x} \mathrm{g}$ for $5 \mathrm{~min}$ at $4^{\circ} \mathrm{C}$ to obtain the cell pellet. After washing with sterile PBS, the supernatant was discarded and cells were resuspended in DMEM (cat. no. 11995065; Gibco; Thermo Fisher Scientific, Inc.) supplemented with 10\% human serum (HS; serotype $\mathrm{AB}^{+}$, obtained from healthy donors after informed consent was signed) and antibiotic-antifungal (penicillin $100 \mathrm{U} / \mathrm{ml}$, streptomycin $100 \mu \mathrm{g} / \mathrm{ml}$ and amphotericin B $0.25 \mu \mathrm{g} / \mathrm{ml}$; cat. no. 15240062; Gibco; Thermo Fisher Scientific, Inc.). Cells were maintained in $25-\mathrm{cm}^{2}$ culture flasks (cat. no. 430639 ; Corning, Inc.) at $37^{\circ} \mathrm{C}$ with $5 \% \mathrm{CO}_{2}$ for $24 \mathrm{~h}$. The supernatant with unattached cells was obtained from the culture flasks and incubated in a new $25-\mathrm{cm}^{2}$ flask at $37^{\circ} \mathrm{C}$ and $5 \% \mathrm{CO}_{2}$ (subculture) for 5 days. The subculture was washed with sterile PBS to remove traces of erythrocytes and other suspended cells and was finally maintained at $37^{\circ} \mathrm{C}$ and $5 \% \mathrm{CO}_{2}$ with a change of medium every 2 days until cells reached $90 \%$ confluence; they were then trypsinized (cat. no. 15050065; Gibco; Thermo Fisher Scientific, Inc.) and expanded in $150-\mathrm{cm}^{2}$ culture flasks (cat. no. 430823; Corning, Inc.).

Proliferation analysis. Proliferation analysis of Ad-MSCs under HS or FBS conditions was performed with alamarBlue (cat. no. DAL1100; Invitrogen; Thermo Fisher Scientific, 
Inc.). Proliferation was tested in biological triplicate every $24 \mathrm{~h}$ for 6 days. Cells were seeded in 96-well plates (cat. no. 3300; Corning, Inc.) at 10,000 cells/well with DMEM (cat. no. 11995065; Gibco; Thermo Fisher Scientific, Inc.) and $10 \%$ HS or $10 \%$ FBS (cat. no. 16140071; Gibco; Thermo Fisher Scientific, Inc.) and incubated at $37^{\circ} \mathrm{C}$ with $5 \% \mathrm{CO}_{2}$. For each time point, medium was replaced with $10 \%$ alamarBlue solution in DMEM, after which cells were incubated for $2 \mathrm{~h}$ at $37^{\circ} \mathrm{C}$ and the supernatant was transferred to 96 -well black plates (cat. no. 3915; Corning, Inc.). The fluorescence signal of the supernatant was measured at $525 \mathrm{~nm}$ using a Glo-Max multi detection system (Promega Corporation).

Expression of multipotential MSC markers. To evaluate the undifferentiated stage (multipotential) of the isolated MSCs, Nanog homeobox (NANOG) and octamer-binding transcription factor (OCT3/4), which are transcription factors involved in self-renewal and maintenance of the undifferentiated stage of MSCs $(21,22)$, were evaluated by immunofluorescence (IF). Stage-specific embryonic antigen 4 (SSEA4), a cell surface antigen of embryonic stem cells, was included as a negative control $(23,24)$. The isolated cells in passage 3 were seeded in duplicate with a seeding density of 10,000 cells/well in 8-well culture chambers (cat. no. 154534; Nunc; Thermo Fisher Scientific, Inc.). Once they reached $90 \%$ confluence, the culture medium was removed and the cells were washed with PBS followed by $5 \mathrm{~min}$ of incubation at room temperature with cytoskeleton buffer (CB) composed of the following: 2-ethanesulfonic acid (10 mM), $\mathrm{NaCl}(150 \mathrm{mM})$, EGTA $(5 \mathrm{mM}), \mathrm{MgCl}$ $(5 \mathrm{mM})$ and glucose $5(\mathrm{mM})$. CB was then removed and fixation was performed with $3 \%$ formaldehyde (cat. no. HT501128; Sigma-Aldrich; Merck KGaA) diluted in CB for $10 \mathrm{~min}$ at room temperature. Cells were permeabilized with $0.05 \%$ Triton X-100 (cat. no. T8787; Sigma-Aldrich; Merck KGaA) for 5 min, then washed with PBS and blocked for non-specific sites by treatment with $0.5 \%$ bovine serum albumin (cat. no. A3294; Sigma-Aldrich; Merck KGaA) for $30 \mathrm{~min}$ at room temperature.

Cells were incubated overnight at $4^{\circ} \mathrm{C}$ with a $1: 100$ dilution of specific primary antibodies against NANOG (cat. no. sc-293121), OCT3/4 (cat. no. sc-5279) and SSEA4 (cat. no. sc-21704; all from Santa Cruz Biotechnology, Inc.) in a wet chamber. Samples were then washed with PBS-Tween $20(0.01 \%)$ and incubated with anti-mouse IgG secondary antibody conjugated with Alexa Fluor $^{\circledR} 488$ (cat. no. ab150113; 1:1,000) and rhodamine phalloidin (cat. no. ab235138; 1:60; all from Abcam) for $2 \mathrm{~h}$ at room temperature to stain actin filaments. After the final wash, assembly of the culture slides was performed with VectaShield (cat. no. H-1200-10; Vector Laboratories, Inc.; Maravai LifeSciences) mounting medium containing DAPI as a counterstain for nuclei. The slides were observed under a fluorescence microscope (magnification, x20; Olympus AX70; Olympus Corporation) and whole sections were analyzed. Selected markers were expected to exhibit green fluorescence for NANOG and OCT3/4, with a counterstain of blue fluorescence for the nuclei and red for actin filaments of the cytoskeleton.

Biphasic scaffold manufacturing. Bovine cartilage matrix was obtained from the scrapings of femoral condyles from 19 fresh bovine knees obtained through a certified slaughterhouse and decellularized with hypotonic buffers (19). Full decellularization was assured by $\mathrm{H} \& \mathrm{E}$ staining. Bovine bone chips were obtained by perforation of the same bovine knees after cross-sectional slicing of the condyle area, followed by decellularization with hydrogen peroxide according to the decellularization method described by Pérez-Silos et al (25) to avoid host rejection of the material (26).

The 3D biphasic scaffolds were assembled as previously described (19) to generate a 2-mm cartilage upper phase and a 4-mm bone phase at the bottom. The 1:1 mixture of decellularized bovine cartilage matrix and $\mathrm{NaCl}$ with a particle size of 77-177 $\mu \mathrm{m}$, selected by sifting through sieves (Mont Inox), was placed inside polytetrafluoroethylene (PTFE) molds with an internal diameter of $6 \mathrm{~mm}$, previously sealed at the bottom with sealing film (cat. no. P7793-1EA; Parafilm). The mixture was slightly compacted at the bottom of the mold and $8 \%$ of silk fibroin (cat. no. 5154-20ML; Advanced BioMatrix), previously lyophilized and dissolved in hexafluoroisopropanol (cat. no. 105228-1006; Sigma-Aldrich; Merck KGaA), was added and the mixture was left to rest for $2 \mathrm{~min}$ to achieve a homogeneous distribution between the $\mathrm{NaCl}$ and cartilage matrix. Subsequently, a bone chip was submerged in $90 \%$ methanol; the excess of methanol was removed and the bone chip was slightly compressed over the mixture in the PTFE mold to maintain the union between all of the components. PTFE molds with the mix were covered and left to rest for $24 \mathrm{~h}$, and then the sealing film was removed and molds were submerged in $90 \%$ methanol for $1 \mathrm{~h}$. Biphasic scaffolds were removed from the molds and washed for 3 days in ultrapure water to remove the $\mathrm{NaCl}$ and obtain pores of the desired size (77-177 $\mu \mathrm{m}$ ). The scaffolds were freeze-dried, sterilized with ethylene oxide and stored at room temperature until use.

Ad-MSC chondrogenic differentiation protocol. Ad-MSCs were initially divided into five groups (A to E; Fig. 1) and differentiated in DMEM with added dexamethasone $100 \mathrm{nM}$ (cat. no. D2915-100MG; Sigma-Aldrich; Merck KGaA), L-ascorbic acid $50 \mu \mathrm{g} / \mathrm{ml}$ (cat. no.013-19641; FUJIFILM Wako Pure Chemical Corporation) and insulin-transferrin-selenium $10 \mu \mathrm{g} / \mathrm{ml}$ (cat. no. 25-800-CR; Gibco; Thermo Fisher Scientific, Inc.).

In the first step, all groups were exposed to human recombinant FGF2 (cat. no. SRP4037-50UG; Sigma-Aldrich; Merck $\mathrm{KGaA}$ ) at $10 \mathrm{ng} / \mathrm{ml}$ for 5 days until cells reached $90 \%$ confluence in $150-\mathrm{cm}^{2}$ culture flasks (cat. no. 430823; Corning, Inc.). After this period, human recombinant growth factors IGF1 (100 ng/ml; cat. no. SRP3069-100UG; Sigma-Aldrich; Merck KGaA) and TGF $\beta 1$ (10 ng/ml; cat. no. T7039-2UG; Sigma-Aldrich; Merck KGaA) alone or in combination were added to each one of the five groups, following the scheme presented in Fig. 1. Exposure to growth factors was performed in a monolayer until day 9, following which the cell monolayer was trypsinized and cells were seeded in the chondral phase of the biphasic scaffolds by injection of 300,000 cells/scaffold. The cells in the scaffold were maintained with the exposure scheme in 48-well cell culture plates (cat. no. 142475; Nunc; Thermo Fisher Scientific, Inc.) until day 40. The scaffolds were processed, and reverse transcription-quantitative PCR (RT-qPCR) for chondrogenic and osteogenic markers (by triplicate) and histological techniques at different time points (by duplicate) were performed. 


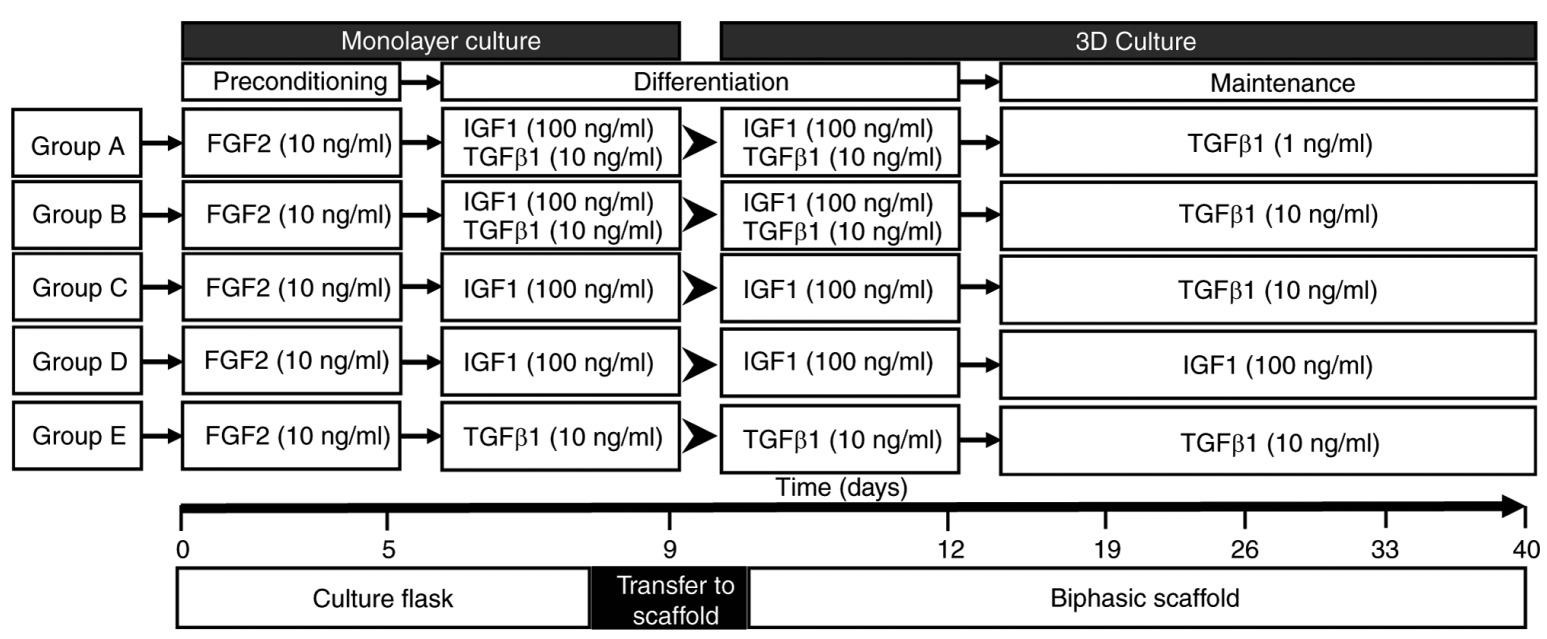

Figure 1. Growth factor treatment schedules designed for chondrogenic differentiation of adipose-derived mesenchymal stem cells. Schematic diagram of the five differentiation scheme groups. Triplicate samples were set up for each time point of marker expression analysis $(0,5,9,12,19,26,33$ and 40 days $)$ and duplicates for each histology analysis timepoint (12, 19, 33 and 40 days). At day 9, cells were transferred from the monolayer to the biphasic scaffold. IGF, insulin-like growth factor; FGF, fibroblast growth factor.

RNA isolation and expression analysis. Total RNA was isolated with TRIzol ${ }^{\circledR}$ reagent (cat. no. 15596018; Invitrogen; Thermo Fisher Scientific, Inc.). The two-phase scaffold was separated into its cartilage and bone phases, cartilage phase was homogenized by cutting it into small pieces with sterile scissors followed by mechanical disaggregation with TissueRuptor II (cat. no. 9002756; Qiagen GmbH) using a steel probe. The homogenized sample was then centrifuged at $14,000 \mathrm{x} \mathrm{g}$ for $10 \mathrm{~min}$ at $4^{\circ} \mathrm{C}$ and the supernatant was collected and processed according to the manufacturer's protocol. The RNA was resuspended in $50 \mu \mathrm{l}$ ultrapure water and the integrity was analyzed via electrophoresis in $1 \%$ agarose gel. The purity and concentration of RNA were determined using a NanoDrop $^{\text {TM }} 1000$ (NanoDrop Technologies; Thermo Fisher Scientific, Inc.).

RNA was retrotranscribed from $1 \mu \mathrm{g}$ of total RNA with the High-Capacity cDNA Reverse Transcription Kit (cat. no. 4368813; Applied Biosystems; Thermo Fisher Scientific, Inc.) following the manufacturer's protocol with the use of random hexamers at a final volume of $20 \mu \mathrm{l}$. The temperature program was as follows: $25^{\circ} \mathrm{C}$ for $10 \mathrm{~min}, 37^{\circ} \mathrm{C}$ for $120 \mathrm{~min}$ and $85^{\circ} \mathrm{C}$ for $5 \mathrm{~min}$. cDNA stored at $-20^{\circ} \mathrm{C}$ until use.

Expression analysis of the differentiation groups was performed at $0,5,9,12,26,33$ and 40 days using three scaffolds for each time point (biological triplicate). The expression levels of the genes SOX9, aggrecan (ACAN), cartilage oligomeric matrix protein (COMP), collagen type II $\alpha 1$ chain (COL2A1), COL10A1 (chondrogenic markers), RUNX2, ALPL, MMP13, COL1A2, COL10A1 and osteopontin (SPP1) (osteogenic markers) were determined. Thy-1 cell surface antigen (THY1; CD90) gene expression (MSC marker) was also assessed. qPCR was performed with mRNA-specific primers previously designed with Oligo 7 software v7.6 (Table I) using $100 \mathrm{ng}$ of cDNA and PowerUp SYBR Green Master Mix (cat. A25776; Applied Biosystems; Thermo Fisher Scientific, Inc.). qPCR was conducted in a StepOnePlus thermal cycler (cat. 4376600; Applied Biosystems; Thermo Fisher Scientific, Inc.) with the following cycling conditions: $50^{\circ} \mathrm{C}$ for $2 \mathrm{~min}$, and 40 cycles of denaturation at $95^{\circ} \mathrm{C}$ for $15 \mathrm{sec}$ and annealing/extension at $60^{\circ} \mathrm{C}$ for $1 \mathrm{~min}$. Results were analyzed with the $2^{-\Delta \Delta \mathrm{Cq}}$ method (27) using GAPDH as an endogenous control.

Histological analysis. Histological analysis in duplicate was performed on the cellularized scaffolds at different time points (12, 19, 33 and 40 days). The scaffolds were withdrawn from the growth medium, washed with PBS and fixed in $10 \%$ formalin solution for $48 \mathrm{~h}$ at room temperature. Scaffolds were decalcified with 14\% EDTA for 7 days, followed by gradual dehydration with acetone-xylol, to be embedded in paraffin. Longitudinal sections $(5 \mu \mathrm{m})$ of the paraffin scaffolds were stained with H\&E (28) to evaluate the cell distribution after 3 days of scaffold cellularization, as well as new matrix formation within the scaffold at the specified time points $(12,19$, 36 and 40 days). Collagen formation and extracellular matrix fibrosis were evaluated with Masson's trichrome staining (29) at the specified time points (12, 19, 36 and 40 days). Slides were observed under a microscope (magnification, x10 and x20; Leica DMRA; Leica Microsystems GmbH) and histological qualitative results were determined by blinded analysis of at least 3 optical fields by a pathology expert.

Statistical analysis. Values are expressed as the mean \pm standard deviation. Statistical analysis was performed with GraphPad Prism 5 software (GraphPad Software, Inc.) using one-way ANOVA with Tukey's post hoc test. $\mathrm{P}<0.05$ was considered to indicate a statistically significant difference.

\section{Results}

Isolation and standardization of the xeno-free cell culture. Isolation of Ad-MSCs was performed from lipoaspirate. Cells obtained after the subculture process exhibited typical MSC characteristics, such as adherence to plastic substrate and fibroblastoid morphology, reaching a high confluence after 10 days of isolation (Fig. 2A). Identification of MSC surface markers CD73, CD90 and CD44, and positive three-lineage differentiation, assessed previously by our research group by Moncada-Saucedo (20). 
Table I. PCR primers designed for mesenchymal, chondrogenic and osteogenic markers.

A, Chondrogenic markers

\begin{tabular}{lll}
\hline Gene & \multicolumn{1}{c}{ Forward primer $\left(5^{\prime}-3^{\prime}\right)$} & \multicolumn{1}{c}{ Reverse primer $\left(5^{\prime}-3^{\prime}\right)$} \\
\hline SOX9 & AACGGCTCCAGCAAGAACAAG & GCTCCGCCTCCTCCACGAAG \\
ACAN & CAACAATGCCCAAGACTACCAG & TTCCACTCGCCCTTCTCGTG \\
COMP & CAGACAATGAACAGCGACCC & GCCTGCCAATACGTTTGCTC \\
COL2A1 & TCATCCAGGGCTCCAATGACGTG & AACAGTCTTGCCCCACTTACCG \\
\hline
\end{tabular}

B, Osteogenic markers

\begin{tabular}{|c|c|c|}
\hline Gene & Forward primer $\left(5^{\prime}-3^{\prime}\right)$ & Reverse primer $\left(5^{\prime}-3^{\prime}\right)$ \\
\hline RUNX2 & GAACTCGTCCGCACCGACAG & ATCGTTACCCGCCATGACAGT \\
\hline ALPL & CGGCCTGGACCTCGTTGACA & ACGTTGTTCCTGTTCAGCTCGTA \\
\hline MMP13 & CGCCAGACAAATGTGACCCTT & AAAACAGCTCCGCATCAACC \\
\hline COL10A1 & CGCCAGACAAATGTGACCCTT & AAAACAGCTCCGCATCAACC \\
\hline COL1A2 & TAGAAAGAACCCAGCTCGCACA & GGTTTCGCCAGTAGAGAAATCACA \\
\hline SPP1 & AAGAAGTTTCGCAGACCTGACATCC & TGCACCATTCAACTCCTCGCTTT \\
\hline
\end{tabular}

C, Mesenchymal marker

\begin{tabular}{lrr}
\hline Gene & Forward primer $\left(5^{\prime}-3^{\prime}\right)$ & Reverse primer $\left(5^{\prime}-3^{\prime}\right)$ \\
\hline THY1 & CACACATACCGCTCCCGAAC & CTGATGCCCTCACACTTGACCA \\
\hline
\end{tabular}

$\mathrm{D}$, Endogenous gene

\begin{tabular}{lcc}
\hline Gene & Forward primer $\left(5^{\prime}-3^{\prime}\right)$ & Reverse primer $\left(5^{\prime}-3^{\prime}\right)$ \\
\hline GAPDH & ACAACAGCCTCAAGATCATCAGC & TCACGCCACAGTTTCCCGGAG \\
\hline
\end{tabular}

THY1, Thy-1 cell surface antigen; ACAN, aggrecan; COMP, cartilage oligomeric matrix protein; COL2A1, collagen type II $\alpha 1$ chain; RUNX2, runt-related transcription factor 2; ALPL, alkaline phosphatase; SPP1, osteopontin.

Ad-MSC proliferation was analyzed in the presence of FBS and HS. The relative cell proliferation in HS medium was almost two times higher than that in FBS medium on day 6 of proliferation (Fig. 2B), thereby improving the culture of the cells under xeno-free conditions.

In addition, IF detection of principal transcription factors present in adult isolated stem cells (NANOG and OCT3/4), along with SSEA4 as a negative control, was performed to evaluate the multipotent characteristics of the Ad-MSCs (Fig. 3). IF analysis of isolated Ad-MSCs demonstrated the presence of NANOG and OCT3/4 in the cells; NANOG was observed in both the nuclei and cytoplasm, while OCT3/4 had a specific nuclear compartmentalization. SSEA4 was confirmed to be negative in the adult isolated stem cells.

Osteochondral biphasic scaffold manufacture and cell migration evaluation. The described method allows for the generation of easily reproducible biphasic scaffolds (Fig. 4A), able to maintain the cartilage structure until the differentiated cells secrete the new cartilage matrix. Migration analysis of pre-differentiated cells indicated that these cells have a strong preference for the chondral phase (Fig.4B), maintaining tropism for the bioactive material of the chondral phase (decellularized bovine cartilage matrix), as indicated in previous experiments performed by our research group (19). H\&E staining suggested that Ad-MSC cells migrated into the scaffold and 1 or 2 cells were located in the empty spaces corresponding to the native chondral lagoons, forming isogenic groups (Fig. 4C). These results demonstrated that these cells were able to adopt a cellular conformation similar to that of native cartilage tissue.

Sequential exposure differentiation and expression analysis. Evaluation of differentiation and hypertrophy of Ad-MSCs was performed by measuring the relative expression of chondrogenic and osteogenic mRNA markers via RT-qPCR. The expression levels of the mesenchymal marker THY1 increased during preconditioning with FGF2, with a subsequent decrease when FGF2 was removed at early culture times in the 3D scaffold to finally increase to its maximum at 26 days of differentiation and decrease in the late stages of differentiation (Fig. 5A). 

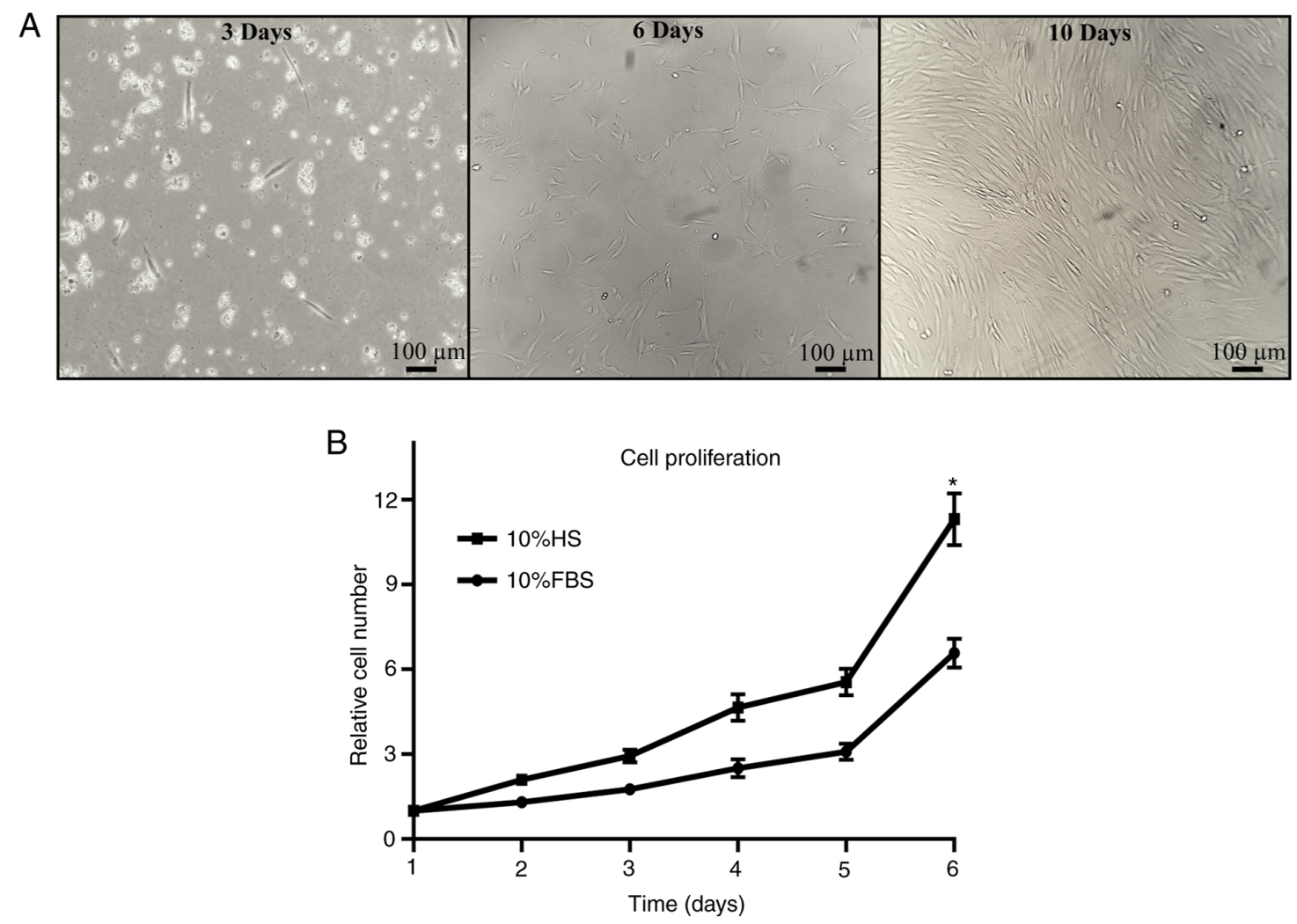

Figure 2. Isolation and proliferation of Ad-MSCs. Ad-MSCs were observed after isolation from adipose tissue and relative proliferation was assessed under HS and FBS conditions. (A) Cells were evaluated for cell morphology and confluence at 3,6 and 10 days after isolation. Red blood cells were observed at day 3 as small circular cells. Ad-MSCs displayed adherence to culture flasks, with a fibroblastoid morphology (scale bars, $100 \mu \mathrm{m}$ ). (B) Relative cell proliferation was analyzed for 6 days; the relative proliferation increased significantly with cell culture under HS conditions. " $\mathrm{P}<0.05$ vs. $10 \%$ FBS. Ad-MSCs, adipose-derived mesenchymal stem cells; HS, human serum.

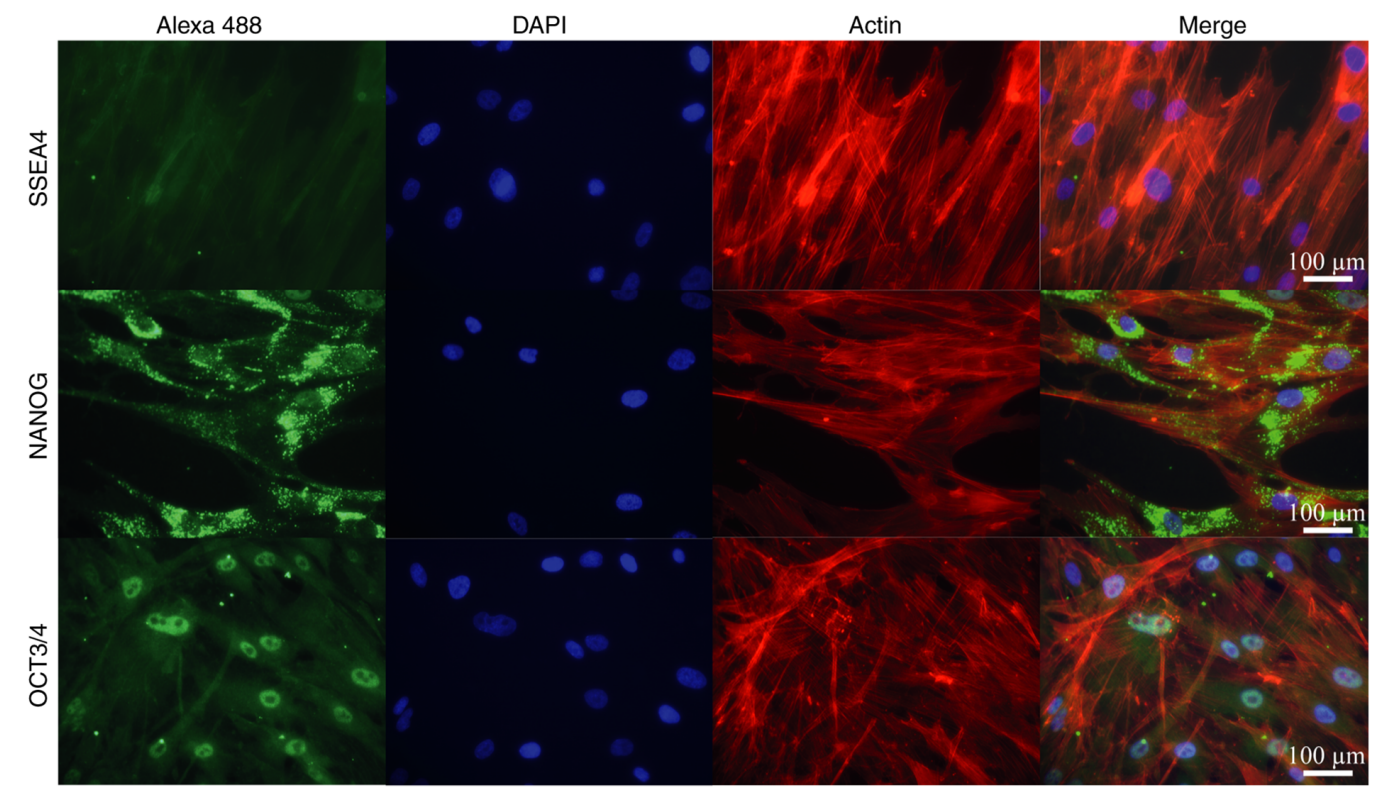

Figure 3. Immunofluorescence analysis of pluripotent factors in adipose-derived MSCs. MSC pluripotential markers NANOG and OCT3/4 were visualized by secondary antibody conjugated with Alexa 488 (green fluorescence). The negative control SSEA4 did not exhibit a signal in the cells. Nuclei and actin filaments were visualized with DAPI and rhodamine phalloidin, respectively (scale bars, $100 \mu \mathrm{m}$ ). MSCs, mesenchymal stem cells; NANOG, Nanog homeobox; OCT3/4, octamer-binding transcription factor; SSEA4, stage-specific embryonic antigen 4.

Analysis of chondrogenic marker expression (Fig. 5B) demonstrated maximal expression of SOX9 between 12 and 19 days of exposure, decreasing over time in all scheme groups. Furthermore, the expression of the chondrogenic markers ACAN and COL2A1 increased for up to 19 days of differentiation, reaching its maximum level at 26 days, 


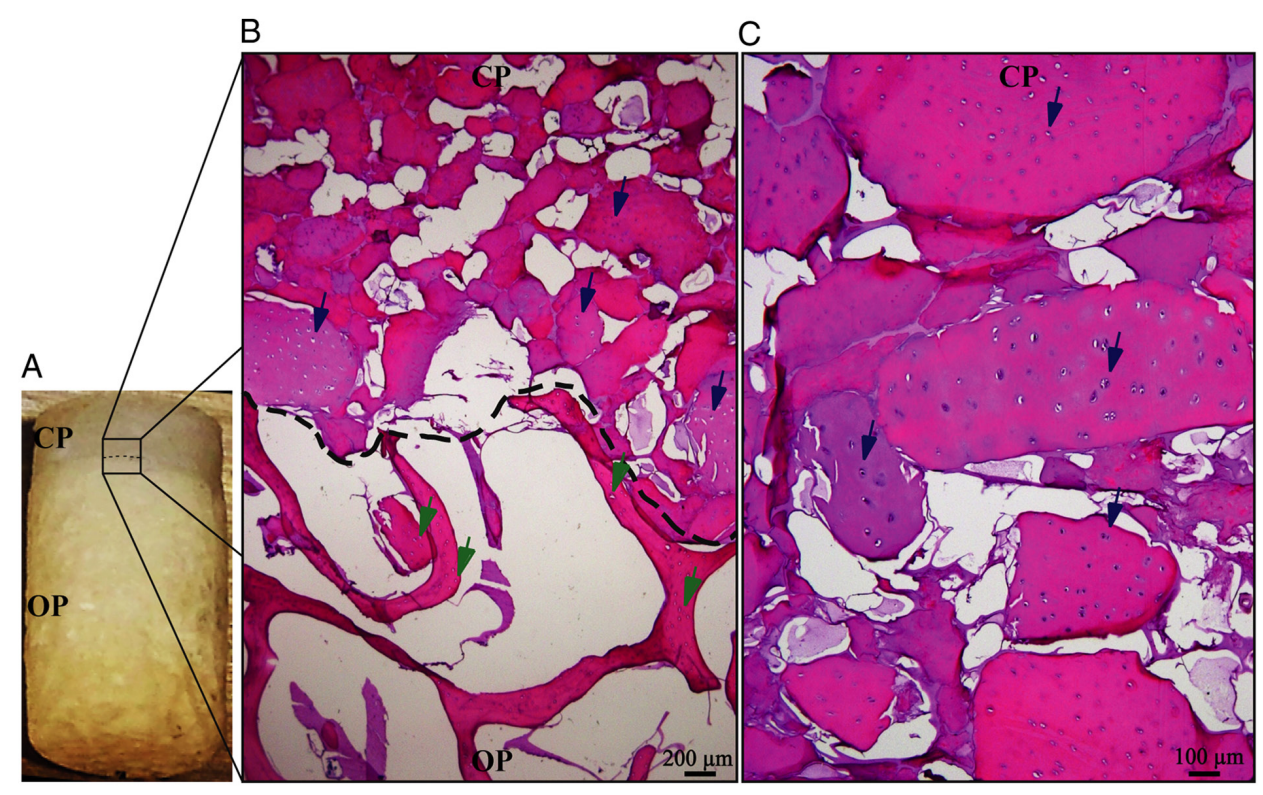

Figure 4. Cell migration into the biphasic scaffold. Cell migration inside the biphasic scaffolds was analyzed by H\&E staining. (A) Macroscopic view of the biphasic scaffold, in which the CP and OP may be observed. (B) Microscopic view of the interphase between the CP and OP. The dotted line indicates the phase borderline and Ad-MSCs were present only in the CP of the scaffold (blue arrows). No cells were present in the OP, where empty lacunae can be observed (green arrows) (scale bar, $200 \mu \mathrm{m}$ ). (C) Zoom view of the CP. Ad-MSCs may be observed inside the cartilage lacunae (blue arrows), individually aligned or forming isogenic groups (scale bar, $100 \mu \mathrm{m}$ ). Ad-MSCs, adipose-derived mesenchymal stem cells; CP, chondrogenic phase; OP, osteogenic phase.
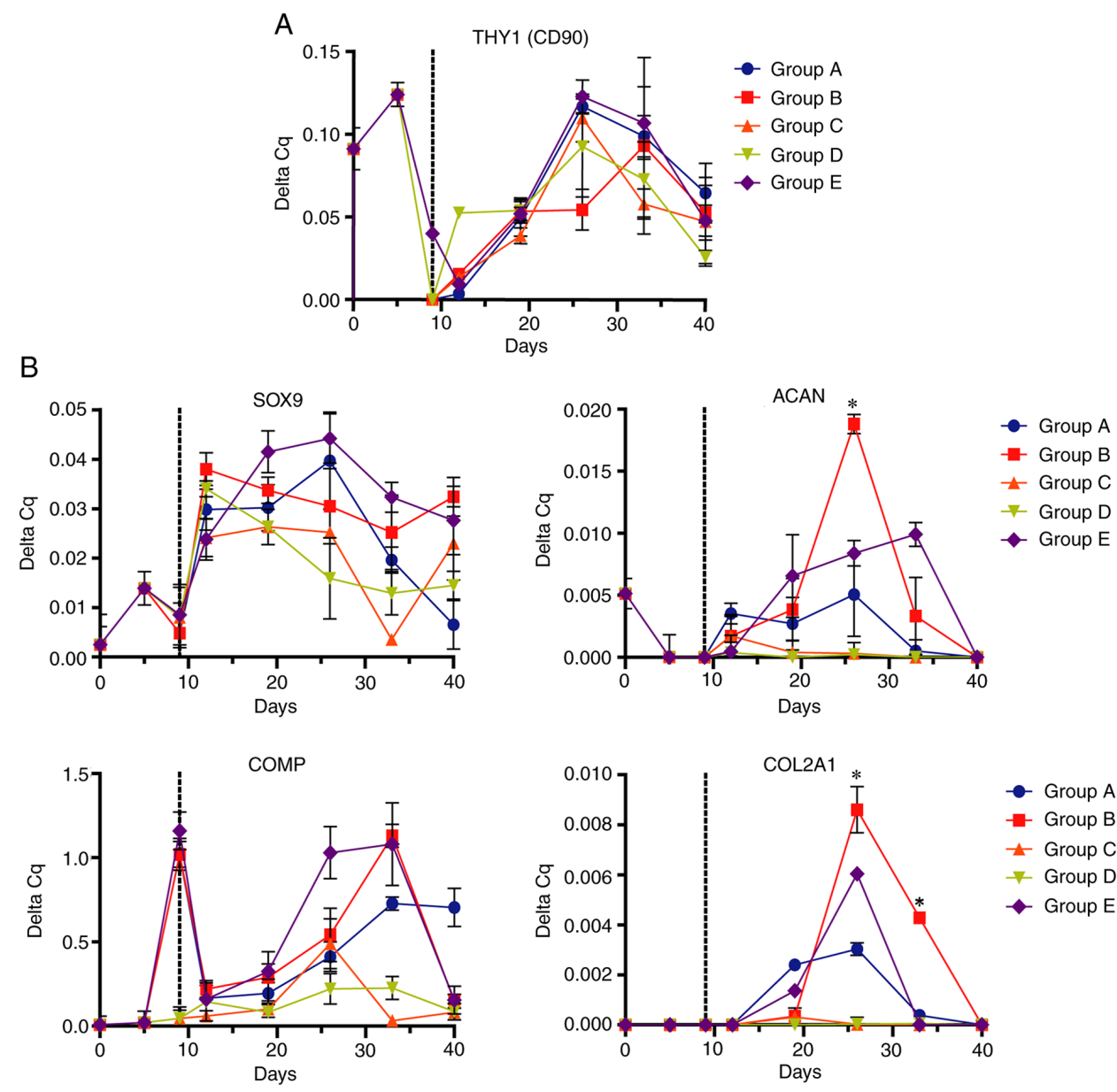

Figure 5. Expression of mesenchymal and chondrogenic markers in Ad-MSCs determined by reverse transcription-quantitative PCR. Ad-MSCs subjected to the differentiation schemes A-E were analyzed for (A) mesenchymal marker [THY1 (CD90)] and (B) chondrogenic marker (SOX9, ACAN, COMP and COL2A1) expression at different time points of exposure. Dotted lines indicate the change from monolayer to biphasic scaffold. "P $<0.05$ (group B vs. all other groups). Ad-MSCs, adipose-derived mesenchymal stem cells; THY1, Thy-1 cell surface antigen; ACAN, aggrecan; COMP, cartilage oligomeric matrix protein; COL2A1, collagen type II $\alpha 1$ chain. 

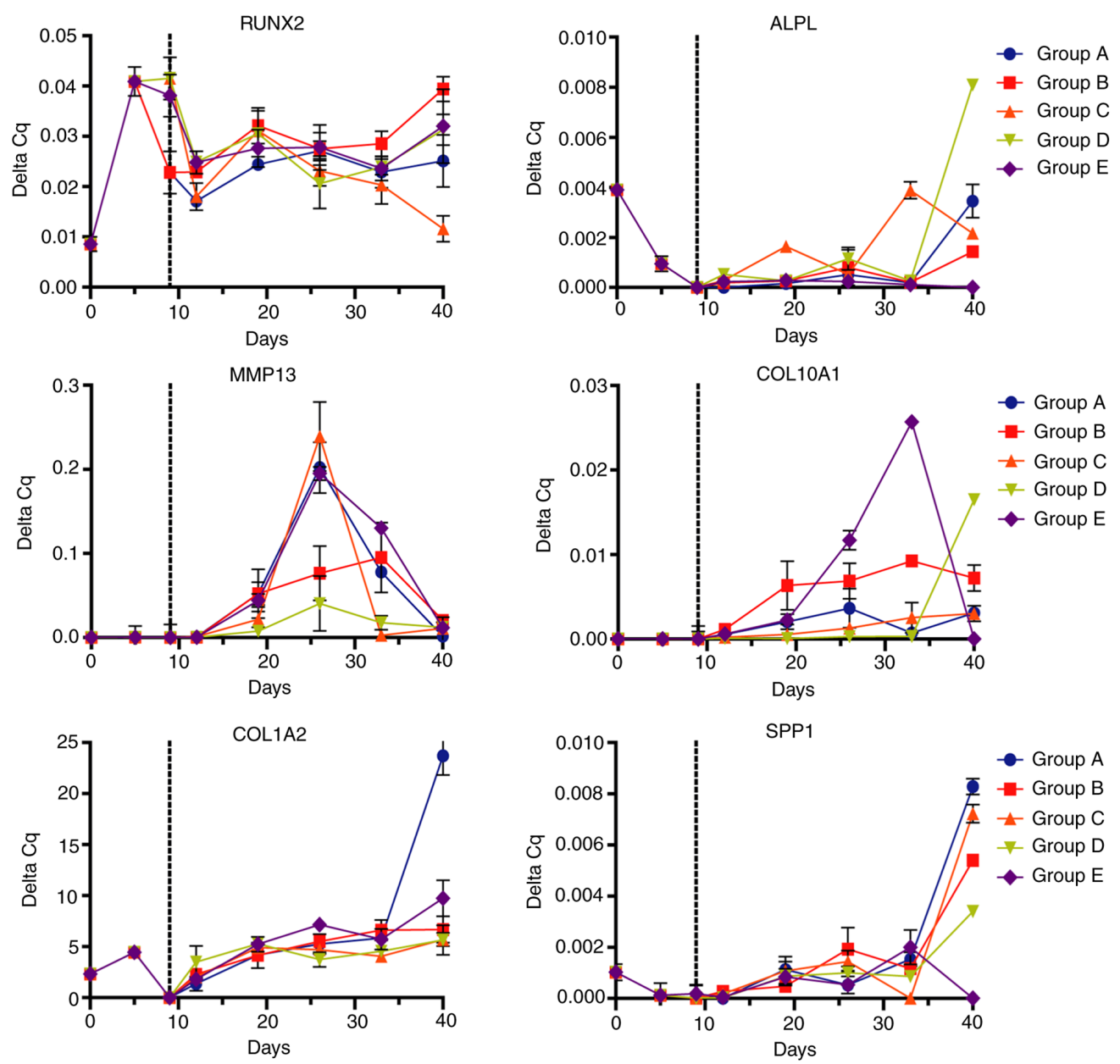

Figure 6. Expression of osteogenic markers in Ad-MSCs determined by reverse transcription-quantitative PCR. Ad-MSCs subjected to the differentiation schemes A-E were analyzed for osteogenic markers (RUNX2, ALPL, MMP13, COL10A1, COL1A2 and SPP1) at different time points of exposure. Dotted lines represent the change from monolayer to biphasic scaffold. Ad-MSCs, adipose-derived mesenchymal stem cells; RUNX2, runt-related transcription factor 2; COL1A2, collagen type I $\alpha 2$ chain; ALPL, alkaline phosphatase; SPP1, osteopontin.

to decrease at 33 days. At this point, ACAN and COL2A1 (two of the main components of the cartilage matrix) had an increased expression in group B compared with other differentiation schemes. COMP (chondrogenic marker) underwent a 'reset' or decreased expression during the monolayer culture transfer to the biphasic scaffold, before increasing in the 3D scaffolds; high expression was sustained in groups B and E. The expression patterns of the chondrogenic markers indicated that all groups underwent a process of chondrogenic differentiation; however, group B [FGF2 $(10 \mathrm{ng} / \mathrm{ml})$ followed by IGF1 $(100 \mathrm{ng} / \mathrm{ml}) / \mathrm{TGF} \beta 1(10 \mathrm{ng} / \mathrm{ml})$ followed by TGF $\beta 1$ $(10 \mathrm{ng} / \mathrm{ml})]$ had the highest capacity towards chondrocyte differentiation.

On the other hand, analysis of osteogenic markers (Fig. 6) provided different expression signatures depending on the differentiation protocol. RUNX2 expression was increased since the preconditioning with FGF2 and maintained across the differentiation stages. Expression analysis indicated a linear and steady expression of RUNX2 until day 40. The osteogenic marker ALPL maintained a relatively low expression for 33 days with a high increase at 40 days, with notably increased expression in the D group [IGF1 $(100 \mathrm{ng} / \mathrm{ml})]$. The expression of the metalloprotease MMP13 increased to a maximum at 26 days, while COL10A1 expression started at day 19, increasing to a maximum between 26 and 33 days, particularly in group E [TGF $\beta 1(10 \mathrm{ng} / \mathrm{ml})]$ and decreasing at day 40. COL1A2 and SPP1 displayed a similar expression pattern, maintaining reduced expression throughout the differentiation process with an increase at day 40 , where group A exhibited the biggest increase of these markers.

Histological analysis. Histological analysis revealed new acidophilic amorphous material formed over time, which produced a homogeneous tissue similar to native cartilage (Fig. 7). In addition, the biodegradability of silk fibroin was observed over time, with only traces on day 40 . The remodeling of the cartilage matrix was evaluated with Masson's trichrome staining, where collagen was stained blue and fibrous tissue turned into a reddish color. In most groups, collagen decreased over time, while the amount of fibrous matrix increased at later stages (Fig. 8).

Group B maintained the most stable collagen matrix until day 33; however, an apparent fibrotic process began between days 33 and 40. In groups A, C, D and E, the fibrotic process started before day 33, with a small amount of collagen and high calcification observed at day 40 . These observations suggested that, despite the presence of certain hypertrophic markers, group B maintained the lowest levels of osteogenic 


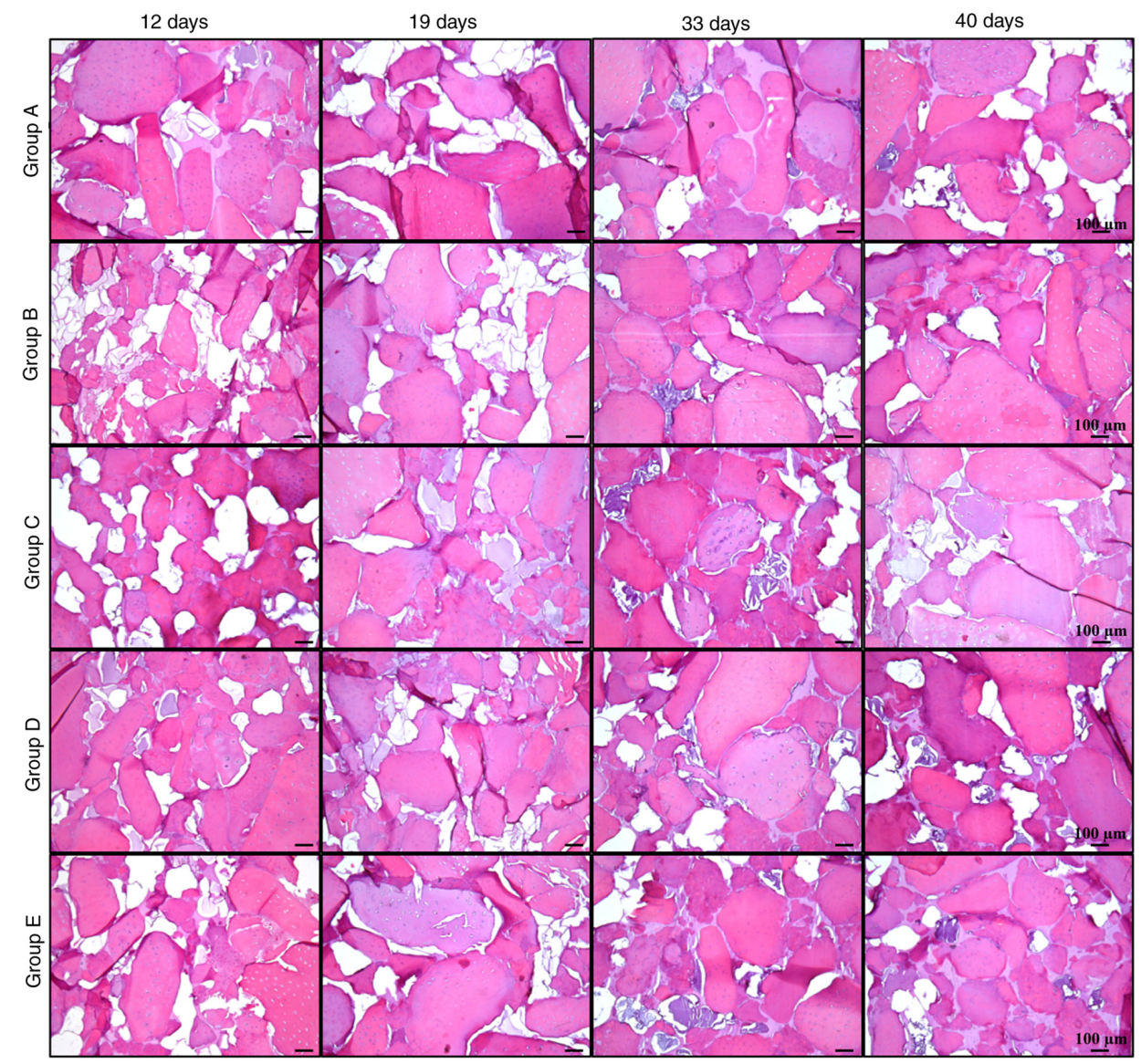

Figure 7. H\&E staining of cellularized biphasic scaffolds. Matrix formation in cellularized biphasic scaffolds subjected to the aforementioned differentiation schemes was analyzed by H\&E staining at different times of exposure (12, 19, 33 and 40 days). The generation of a filling tissue may be observed as an amorphous and acellular tissue between cartilage matrix fragments (scale bar, $100 \mu \mathrm{m}$ ).

expression, while it had higher expression of chondrogenic markers compared with the other groups, retaining its properties until day 33 at the histological level. It was indicated that group B was subjected to the most optimal protocol of growth factor application for chondrogenic differentiation of Ad-MSCs with conditions suitable for human use.

\section{Discussion}

Native cartilage properties hinder its regenerative abilities once tissue reaches maturity and, despite being generated by a single cellular lineage, the medical approaches to regenerate a damaged area face a big challenge that has not been surpassed $(30,31)$. MSCs are undifferentiated cells with the ability to proliferate, migrate and differentiate into different cell lineages. In vivo, these cells support the maintenance, renewal and regeneration of human tissues (32). For this reason, isolation and in vitro differentiation of MSCs is a promising therapy for the regeneration of most human tissues $(18,33,34)$. However, optimal culture and differentiation conditions for this purpose are still in development $(35,36)$.

MSCs may be isolated from multiple human tissues (bone marrow, dental pulp and umbilical cord) (37). However, adipose tissue, usually obtained from surgical waste, is easily accessible and contains a relatively high number of MSCs, with adequate properties for cell culture, proliferation, differentiation and minimum ethical considerations (38), which may be used to generate a chondrocyte-like phenotype through its stimulation for chondrogenesis.

Biological chondrogenesis is regulated by signaling molecules (growth factors), and by cell-cell and cell-matrix interactions. In vitro models of MSCs are capable of inducing chondrogenic differentiation by the use of growth factors and/or biomaterials $(39,40)$. In the present study, it was proposed that the simultaneous use of a combination of growth factors and matrix stimuli (bioactive scaffold) on Ad-MSCs may achieve stable chondrogenic differentiation, with the aim of developing a long-term therapy for human cartilage injuries, in the form of a medical implant loaded with pre-differentiated Ad-MSCs, to generate a medical implant capable of assisting in cartilage regeneration. The scaffolds should have the following properties: i) Biocompatibility with the adjacent tissue; ii) biodegradability; iii) allow cellular migration and adhesion; and iv) ability to resist the mechanical load until the tissue is fully regenerated $(5,41)$. To achieve these properties, a biphasic scaffold with decellularized cartilage as a bioactive ingredient was developed by our group, which has been demonstrated to promote MSC migration, adhesion and cell-matrix signaling that may improve chondrogenic differentiation $(19,42)$. Silk fibroin was used as the adhesive material to hold together the fragments of cartilage. It had the properties of being able to generate pores for cell migration and hold together bone and cartilage phases, as well as flexibility to allow mechanical load (43). 


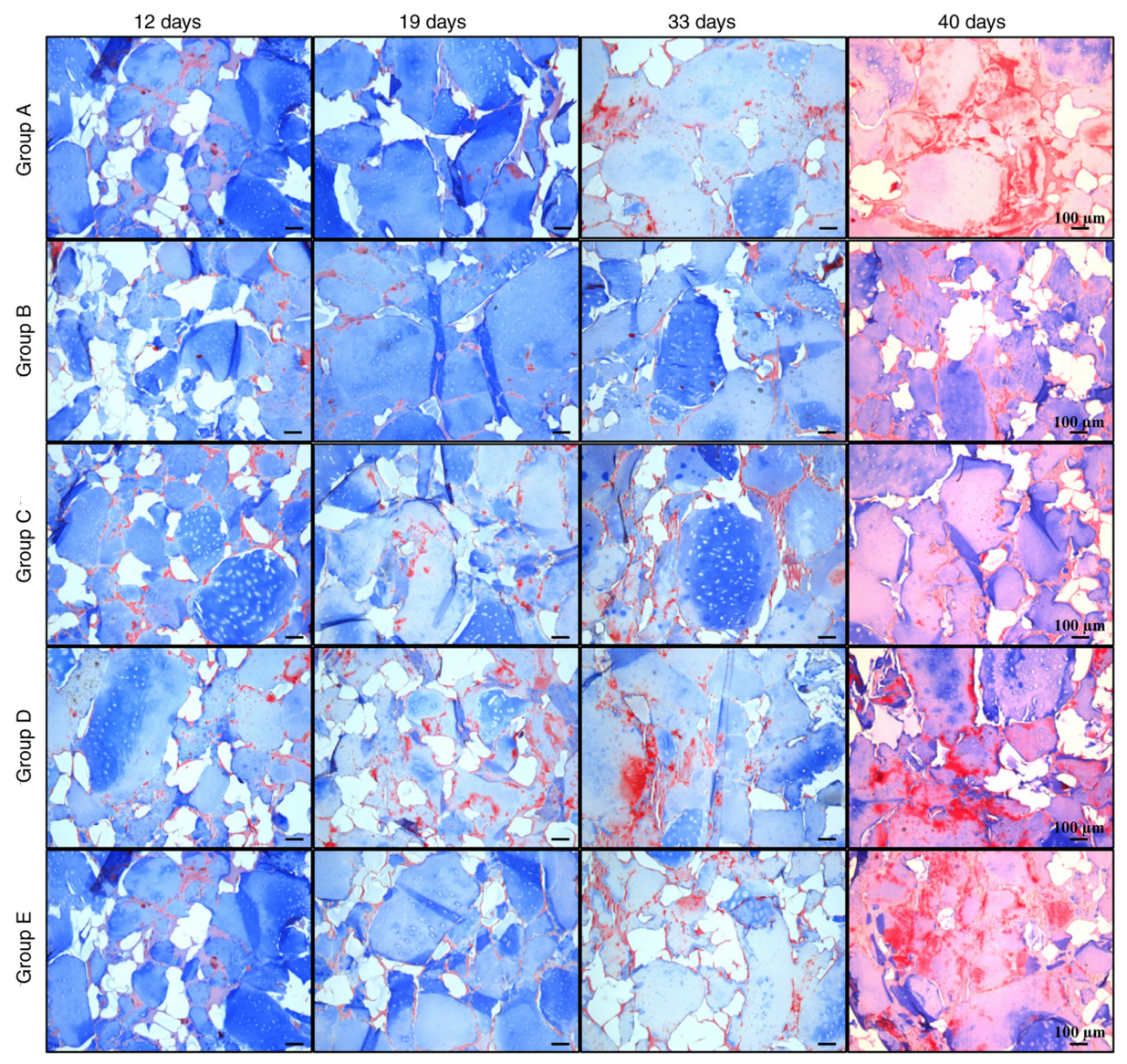

Figure 8. Masson's trichrome staining of cellularized biphasic scaffolds. Matrix formation in cellularized biphasic scaffolds exposed to the aforementioned differentiation schemes was analyzed by Masson's trichrome staining at different times of exposure (12, 19, 33 and 40 days). Collagen matrix with blue staining and fibrous tissue with red staining may be observed (scale bar, $100 \mu \mathrm{m}$ ).

In the present study, the biphasic scaffolds developed had an upper 2-mm thick phase that simulates native cartilage conditions for further implantation, with native cartilage characteristics, such as flexibility, water retention and mechanical resistance to compression (25). The lower 4-mm thick phase of decellularized bone matrix chips served as support for the cartilage phase implantation and integration of cartilage with adjacent tissue. Pre-differentiated Ad-MSCs were introduced into the biphasic scaffold via direct injection of a cell suspension into the chondral phase of the biphasic scaffold, where the pore size, growth conditions and cartilage substrate allowed the migration of cells within the whole scaffold.

For efficient differentiation, a precise balance of chondrogenic and osteogenic factors with temporal changes in the local microenvironment is required (41). RUNX2 is necessary at the first step of differentiation (together with SOX9) to achieve chondrogenic differentiation, also acting as an osteogenic marker after differentiation and at the beginning of the hypertrophic process (44). In addition, native embryonic cells express RUNX2 during the early stages of chondrocyte differentiation, and the generation of mice deficient in RUNX2 leads to a lack of chondrocyte maturation (45). Thus, a proper combination of microenvironment modulation, the appropriate stimuli and an adequate period of exposure are necessary for the maintenance of a stable phenotype.

Previous research has demonstrated that the addition of FGF2 in the expansion phase of MSC culture increases their proliferation, and predisposes cells to undergo chondrocyte differentiation and matrix secretion in a SOX9-independent mechanism, by its coupling to the FGF receptor (46-48). In addition, IGF1, a growth factor commonly used for chondrogenic differentiation, is capable of MSC differentiation and increase of extracellular matrix secretion at the first stages of differentiation, but is also one of the principal promoters of the hypertrophic process and matrix replacement in the late stages of chondrogenic differentiation; that is why IGF1 needs to be removed from the differentiation scheme after the first stages. On the other hand, TGF $\beta 1$ inhibits hypertrophic differentiation (49), and promotes SOX9 activation and chondrogenic differentiation, with a synergistic effect with IGF1 (50) in the first stages of biological MSC differentiation to chondrocytes $(9,51)$.

In the present study, all of the tested schemes achieved differentiation of Ad-MSCs to a chondrocyte-like phenotype; however, there were differences between group schemes, depending on the sequential order and concentration of the growth factors. The expression analysis and histological results indicated that group B [FGF2 $(10 \mathrm{ng} / \mathrm{ml})$, followed by a combination of IGF1 $(100 \mathrm{ng} / \mathrm{ml}) / \mathrm{TGF} \beta 1(10 \mathrm{ng} / \mathrm{ml})$ and a final exposure step of TGF $\beta 1$ alone $(10 \mathrm{ng} / \mathrm{ml})]$ led to a more efficient chondrogenesis and decreased hypertrophic progression.

The use of IGF1 at a continuous dose led to the lowest degree of differentiation and matrix generation, while the synergistic effect of the use of IGF1 plus TGF $\beta 1$ in the differentiation of MSCs to the chondrocyte phenotype (50), which was validated 
by the expression analysis of group D (with IGF1 alone) and group E (with TGF $\beta 1$ ), the combination of which (group B) achieved preferable differentiation results.

Maintaining differentiated cells with low levels of TGF $\beta 1$ (1 ng/ml) (group A) failed to prevent endochondral ossification, leading to the highest levels of certain osteogenic markers. This may be due to the following: i) An insufficient concentration of TGF $\beta 1$ to maintain the chondrogenic phenotype and to avoid endochondral ossification; ii) natural degradation of the growth factor over time; iii) a lower rate of diffusion inside the biphasic scaffold; or iv) a low ratio between the TGF $\beta 1$ concentration and cell number after proliferation inside the scaffold. Finally, a higher concentration of TGF $\beta 1(10 \mathrm{ng} / \mathrm{ml})$ in the candidate scheme (group B) maintained chondrogenic differentiation while cell hypertrophy was decreased, even under extensive growing times (until $>33$ days).

The unexpected behavior of the CD90 mesenchymal marker along the exposure period is consistent with the study by Hagmann et al (46), who reported that the addition of FGF2 to the culture medium alters the expression patterns of the CD90 marker in MSCs.

Comparison among the test conditions for differentiation used in the present study indicated that group B had the most effective differentiation potential towards more phenotypically stable chondrocytes. However, an important limitation of the present study was the lack of a non-differentiated group for RT-qPCR and histology, to determine the absolute values in the differentiation groups in comparison to MSCs without differentiation.

For the adequate clinical use of regenerative therapy, it is important that isolation and culture methods are performed under conditions that may be extrapolated for medical use (xeno-free conditions), which allows the use of Ad-MSCs for a wide range of clinical applications, minimizing the possibility of an adverse reaction or host rejection, in addition to inhibiting changes in molecular signaling pathways. The present study focused on chondrocyte differentiation under clinically relevant conditions, with the use of decellularized materials and animal-free medium conditions with the use of HS (to avoid cellular signaling changes and immune response), which also demonstrated improved proliferation compared with FBS conditions.

In conclusion, the present results demonstrated that the use of clinically relevant conditions, together with an improved differentiation protocol of growth factors in sequence and concentrations to emulate biological chondrogenesis (group B), in a 3D scaffold that simulates native cartilage, allows the possible use of these differentiated cells in an implant for cartilage damage. Future perspectives of this work include pre-clinical testing of the present method, the use of decellularized human cartilage and bone materials, and cell differentiation in a porcine model of cartilage damage to examine the safety, biodegradability and regenerative capacity of the technique of differentiation in the 3D scaffold.

\section{Acknowledgements}

The authors thank Dr Sergio Lozano-Rodriguez (Faculty of Medicine and University Hospital 'Dr José E. González', Autonomous University of Nuevo Leon) for his help in reviewing the manuscript.

\section{Funding}

This work was supported by CONACyT (grant no. SALUD2014-01-233365).

\section{Availability of data and materials}

The datasets used and/or analyzed during the current study are available from the corresponding author on reasonable request.

\section{Authors' contributions}

JLA and LFM conceptualized the study, acquired funding and administered the project. AGR, VPS, NKMS performed the experiments. AGR, VPS, NKMS, VJRD and RRP performed the formal analysis. VJRD and AGR performed histological analysis. YCG examined the patients, collected the samples and was involved in the isolation of Ad-MSCs. CNSD, AMRE, RST, HL, VPM, ACM, RRP and IAMM contributed to the study conception and design. VPS and NKMS analyzed and approved the authenticity of the raw data. All authors have read and approved the final manuscript.

\section{Ethics approval and consent to participate}

The present study was approved by the Institutional Ethics and Research Committees of the Faculty of Medicine and University Hospital 'Dr José E. González' of the Autonomous University of Nuevo Leon (Monterrey, México; registry no. PI17-00360). All patients provided written informed consent for the use of their tissues.

\section{Patient consent for publication}

Not applicable.

\section{Competing interests}

The authors declare that they have no competing interests.

\section{References}

1. Medvedeva EV, Grebenik EA, Gornostaeva SN, Telpuhov VI, Lychagin AV, Timashev PS and Chagin AS: Repair of damaged articular cartilage: Current approaches and future directions. Int J Mol Sci 19: 2366, 2018.

2. Musumeci G, Mobasheri A, Trovato FM, Szychlinska MA, Graziano AC, Lo Furno D, Avola R, Mangano S, Giuffrida R and Cardile V: Biosynthesis of collagen I, II, RUNX2 and lubricin at different time points of chondrogenic differentiation in a $3 \mathrm{D}$ in vitro model of human mesenchymal stem cells derived from adipose tissue. Acta Histochem 116: 1407-1417, 2014.

3. Sanchez Naranjo JC: Fisiología del condrocito articular. Rev Colomb Reumatol 15: 21-33, 2008.

4. Devitt BM, Bell SW, Webster KE, Feller JA and Whitehead TS: Surgical treatments of cartilage defects of the knee: Systematic review of randomised controlled trials. Knee 24: 508-517, 2017.

5. Li YY, Cheng HW, Cheung KM, Chan D and Chan BP: Mesenchymal stem cell-collagen microspheres for articular cartilage repair: Cell density and differentiation status. Acta Biomater 10: 1919-1929, 2014.

6. Delanois RE, Etcheson JI, Sodhi N, Henn RF III, Gwam CU, George NE and Mont MA: Biologic therapies for the treatment of knee osteoarthritis. J Arthroplasty 34: 801-813, 2019.

7. Walker JM: Mesenchymal Stem Cells. 2nd edition. Gnecchi M(ed). Springer, New York, NY, 2016. 
8. Augustyniak E, Trzeciak T, Richter M, Kaczmarczyk J and Suchorska W: The role of growth factors in stem cell-directed chondrogenesis: A real hope for damaged cartilage regeneration. Int Orthop 39: 995-1003, 2015

9. Cicione C, Muiños-López E, Hermida-Gómez T, Fuentes-Boquete I, Díaz-Prado S and Blanco FJ: Alternative protocols to induce chondrogenic differentiation: Transforming growth factor- $\beta$ superfamily. Cell Tissue Bank 16: 195-207, 2015.

10. Zhou N, Li Q, Lin X, Hu N, Liao JY, Lin LB, Zhao C, Hu ZM, Liang X, Xu W, et al: BMP2 induces chondrogenic differentiation, osteogenic differentiation and endochondral ossification in stem cells. Cell Tissue Res 366: 101-111, 2016

11. Sheykhhasan M, Qomi RT and Ghiasi M: Fibrin scaffolds designing in order to human adipose-derived mesenchymal stem cells differentiation to chondrocytes in the presence of TGF- $\beta 3$ Int J Stem Cells 8: 219-227, 2015.

12. Zuo Q, Cui W, Liu F, Wang Q, Chen Z and Fan W: Co-cultivated mesenchymal stem cells support chondrocytic differentiation of articular chondrocytes. Int Orthop 37: 747-752, 2013.

13. Zhong L, Huang X, Karperien M and Post J: The regulatory role of signaling crosstalk in hypertrophy of MSCs and human articular chondrocytes. Int J Mol Sci 16: 19225-19247, 2015.

14. Hata K, Takahata Y, Murakami $T$ and Nishimura R: Transcriptional network controlling endochondral ossification. J Bone Metab 24: 75-82, 2017.

15. Mueller MB and Tuan RS: Functional characterization of hypertrophy in chondrogenesis of human mesenchymal stem cells Arthritis Rheum 58: 1377-1388, 2008

16. Wang X, Li Y, Han R, He C, Wang G, Wang J, Zheng J, Pei M and Wei L: Demineralized bone matrix combined bone marrow mesenchymal stem cells, bone morphogenetic protein- 2 and transforming growth factor- $\beta 3$ gene promoted pig cartilage defect repair. PLoS One 9: e116061, 2014.

17. Solorio LD, Dhami CD, Dang PN, Vieregge EL and Alsberg E Spatiotemporal regulation of chondrogenic differentiation with controlled delivery of transforming growth factor- $\beta 1$ from gelatin microspheres in mesenchymal stem cell aggregates. Stem Cells Transl Med 1: 632-639, 2012.

18. Krinner A and Roeder I: Quantification and modeling of stem cell-niche interaction. Adv Exp Med Biol 844: 11-36, 2014

19. Moncada-Saucedo NK, Marino-Martínez IA, Lara-Arias J, Romero-Díaz VJ, Camacho A, Valdés-Franco JA, Pérez-Silos V, García-Ruiz A, Lin H, Tuan RS, et al: A bioactive cartilage graft of IGF1-transduced adipose mesenchymal stem cells embedded in an alginate/bovine cartilage matrix tridimensional scaffold. Stem Cells Int 2019: 9792369, 2019.

20. Saucedo M and Karina N: Diseño y evaluación in vitro de un implante bifásico bioactivo para la reparación de defectos osteocondrales. Universidad Autónoma de Nuevo León, 2019.

21. Haghighi F, Dahlmann J, Nakhaei-Rad S, Lang A, Kutschka I, Zenker M, Kensah G, Piekorz RP and Ahmadian MR: bFGF-mediated pluripotency maintenance in human induced pluripotent stem cells is associated with NRAS-MAPK signaling. Cell Commun Signal 16: 96, 2018.

22. Zhang W, Sui Y, Ni J and Yang T: Insights into the Nanog gene: A propeller for stemness in primitive stem cells. Int J Biol Sci 12 $1372-1381,2016$

23. Damdimopoulou P, Rodin S, Stenfelt S, Antonsson L, Tryggvason K and Hovatta O: Human embryonic stem cells. Best Pract Res Clin Obstet Gynaecol 31: 2-12, 2016

24. Henderson JK, Draper JS, Baillie HS, Fishel S, Thomson JA, Moore $\mathrm{H}$ and Andrews PW: Preimplantation human embryos and embryonic stem cells show comparable expression of stage-specific embryonic antigens. Stem Cells 20: 329-337, 2002.

25. Pérez-Silos V, Moncada-Saucedo NK, Peña-Martínez V, Lara-Arias J, Marino-Martínez IA, Camacho A, Romero-Díaz VJ, Lara Banda M, García-Ruiz A, Soto-Dominguez A, et al: A cellularized biphasic implant based on a bioactive silk fibroin promotes integration and tissue organization during osteochondral defect repair in a porcine model. Int J Mol Sci 20: 5145, 2019.

26. Blaudez F, Ivanovski S, Hamlet $S$ and Vaquette C: An overview of decellularisation techniques of native tissues and tissue engineered products for bone, ligament and tendon regeneration. Methods 171: 28-40, 2020.

27. Livak KJ and Schmittgen TD: Analysis of relative gene expression data using real-time quantitative PCR and the 2(-Delta Delta C(T)) method. Methods 25: 402-408, 2001.

28. Feldman AT and Wolfe D: Tissue processing and hematoxylin and eosin staining. Methods Mol Biol 1180: 31-43, 2014.
29. Rieppo L, Janssen L, Rahunen K, Lehenkari P, Finnilä MAJ and Saarakkala S: Histochemical quantification of collagen content in articular cartilage. PLoS One 14: e0224839, 2019.

30. Carballo CB, Nakagawa Y, Sekiya I and Rodeo SA: Basic science of articular cartilage. Clin Sports Med 36: 413-425, 2017.

31. Zhang $\mathrm{L}, \mathrm{Hu} \mathrm{J}$ and Athanasiou KA: The role of tissue engineering in articular cartilage repair and regeneration. Crit Rev Biomed Eng 37: 1-57, 2009.

32. Dulak J, Szade K, Szade A, Nowak W and Józkowicz A: Adult stem cells: Hopes and hypes of regenerative medicine. Acta Biochim Pol 62: 329-337, 2015.

33. Xian CJ and Foster BK: Repair of injured articular and growth plate cartilage using mesenchymal stem cells and chondrogenic gene therapy. Curr Stem Cell Res Ther 1: 213-229, 2006.

34. Somoza RA, Welter JF, Correa D and Caplan AI: Chondrogenic differentiation of mesenchymal stem cells: Challenges and unfulfilled expectations. Tissue Eng Part B Rev 20: 596-608, 2014.

35. Danišovič L', Varga I and Polák S: Growth factors and chondrogenic differentiation of mesenchymal stem cells. Tissue Cell 44: 69-73, 2012.

36. Almalki SG and Agrawal DK: Key transcription factors in the differentiation of mesenchymal stem cells. Differentiation 92: 41-51, 2016

37. Fujii S, Miura Y, Iwasa M, Yoshioka S, Fujishiro A, Sugino N, Kaneko H, Nakagawa Y, Hirai H, Takaori-Kondo A, et al: Isolation of mesenchymal stromal/stem cells from cryopreserved umbilical cord blood cells. J Clin Exp Hematop 57: 1-8, 2017.

38. Argentati C, Morena F, Bazzucchi M, Armentano I, Emiliani C and Martino S: Adipose stem cell translational applications: From bench-to-bedside. Int J Mol Sci 19: 3475, 2018

39. Kwon H, Paschos NK, Hu JC and Athanasiou K: Articular cartilage tissue engineering: The role of signaling molecules. Cell Mol Life Sci 73: 1173-1194, 2016.

40. Jiang X, Huang X, Jiang T, Zheng L, Zhao J and Zhang X: The role of Sox9 in collagen hydrogel-mediated chondrogenic differentiation of adult mesenchymal stem cells (MSCs). Biomater Sci 6: 1556-1568, 2018.

41. Demoor M, Ollitrault D, Gomez-Leduc T, Bouyoucef M, Hervieu M, Fabre H, Lafont J, Denoix JM, Audigié F, Mallein-Gerin F, et al: Cartilage tissue engineering: Molecular control of chondrocyte differentiation for proper cartilage matrix reconstruction. Biochim Biophys Acta 1840: 2414-2440, 2014.

42. Xia C, Mei S, Gu C, Zheng L, Fang C, Shi Y, Wu K, Lu T, Jin Y, Lin X and Chen P: Decellularized cartilage as a prospective scaffold for cartilage repair. Mater Sci Eng C Mater Biol Appl 101: 588-595, 2019.

43. Kundu B, Rajkhowa R, Kundu SC and Wang X: Silk fibroin biomaterials for tissue regenerations. Adv Drug Deliv Rev 65: 457-470, 2013

44. Komori T: Runx2, an inducer of osteoblast and chondrocyte differentiation. Histochem Cell Biol 149: 313-323, 2018

45. Mikasa M, Rokutanda S, Komori H, Ito K, Tsang YS, Date Y, Yoshida CA and Komori T: Regulation of Tcf7 by Runx2 in chondrocyte maturation and proliferation. J Bone Miner Metab 29: 291-299, 2011.

46. Hagmann S, Moradi B, Frank S, Dreher T, Kämmerer PW, Richter W and Gotterbarm T: FGF-2 addition during expansion of human bone marrow-derived stromal cells alters MSC surface marker distribution and chondrogenic differentiation potential. Cell Prolif 46: 396-407, 2013.

47. Kabiri A, Esfandiari E, Hashemibeni B, Kazemi M, Mardani M and Esmaeili A: Effects of FGF-2 on human adipose tissue derived adult stem cells morphology and chondrogenesis enhancement in transwell culture. Biochem Biophys Res Commun 424: 234-238, 2012.

48. Correa D, Somoza RA, Lin P, Greenberg S, Rom E, Duesler L, Welter JF, Yayon A and Caplan AI: Sequential exposure to fibroblast growth factors (FGF) 2, 9 and 18 enhances hMSC chondrogenic differentiation. Osteoarthritis Cartilage 23: 443-453, 2015

49. Grafe I, Alexander S, Peterson JR, Snider TN, Levi B, Lee B and Mishina Y: TGF- $\beta$ family signaling in mesenchymal differentiation. Cold Spring Harb Perspect Biol 10: a022202, 2018.

50. Zhou Q, Li B, Zhao J, Pan W, Xu J and Chen S: IGF-I induces adipose derived mesenchymal cell chondrogenic differentiation in vitro and enhances chondrogenesis in vivo. In Vitro Cell Dev Biol Anim 52: 356-364, 2016.

51. Kim YI, Ryu JS, Yeo JE, Choi YJ, Kim YS, Ko K and Koh YG: Overexpression of TGF- $\beta 1$ enhances chondrogenic differentiation and proliferation of human synovium-derived stem cells. Biochem Biophys Res Commun 450: 1593-1599, 2014 